\title{
The case to unify cardiac and vascular surgery
}

Irving L. Kron, MD

\author{
See related article on page \\ 267.
}

From the Department of Surgery, Division of Thoracic and Cardiovascular Surgery, University of Virginia Medical Center, Charlottesville, Va.

Received for publication June 10, 2008; accepted for publication June 10, 2008.

Address for reprints: Irving L. Kron, MD, Professor and Chairman, University of Virginia Health System, Department of Surgery, Division of Thoracic and Cardiovascular Surgery, University of Virginia Medical Center, Lee Street, Room 2753, Box 800679, Charlottesville, VA 22908 (E-mail: ilk@virginia.edu).

J Thorac Cardiovasc Surg 2008;136:271-2 0022-5223/\$34.00

Copyright (C) 2008 by The American Association for Thoracic Surgery

doi:10.1016/j.jtcvs.2008.06.004
I very much enjoyed the editorial by Dr Roberts: "Cardiovascular Surgery a Single Specialty. (General Vascular Surgery \& the Thoracic Surgeon. Ann Thorac. Surg, 1986 May;91(5):471-2)" I agree with the concept with minor exceptions. Several years ago I had written a similar editorial relating to the importance of vascular surgery to the cardiothoracic surgeon. At that time vascular surgery was pretty much ignored by the leadership in our specialty. Dr Roberts makes the case that cardiac and vascular surgery is an appropriate specialty. He also suggests that there is a questionable relationship between cardiac and thoracic surgery. The timing of this editorial is relevant. The thoracic surgical leadership (American Association for Thoracic Surgery/Society of Thoracic Surgeons) has developed a dialogue with the vascular leadership regarding potential training paradigms. The Thoracic Surgical Residency Review Committee and The American Board of Thoracic Surgery are now considering programs that result in joint training. There is nothing really new about this concept. Our program, Stanford, and also the program in Charlotte have previously offered combined training in both specialties. This became more complex when the vascular residency was increased to 2 years. It became much more difficult to convince a trainee to have 4 to 5 years of postgraduate training.

It is about time that our specialty becomes interested in embracing vascular surgery. Perhaps the delay relates to the lack of interest of trainees in cardiothoracic surgery. Most likely, relates to the reduction in the number of patients requiring coronary artery bypass. We need to continue to change to develop our specialty. The fact of the matter is, it is possible to get combined vascular and cardiothoracic training even presently. Vascular surgery now offers a 5-year primary certificate in vascular surgery. This could be followed by 2 or 3 years of cardiothoracic surgical training and finish a practitioner in cardiothoracic and vascular surgery. Therefore, it possible to get combined cardiovascular training in only 7 years after medical school. This is the amount of time required for combined general surgical and thoracic surgical training presently. The Residency Review Committee is interested in such flexible training paradigms, and ideally there will be multiple others that will be available to the potential cardiovascular resident.

Perhaps the most important aspect of all of this is the medical side of vascular surgery. Vascular surgery is not just a surgical specialty. Vascular surgeons have always maintained their interest in being the primary overall physicians for vascular disease. There really is no medical specialty that relates to vascular disease presently. Therefore, the vascular surgeon sees patients primarily, develops treatment options including prevention, and finally helps to determine surgical and interventional therapy for vascular patients. This approach is certainly not present at this time for cardiac surgery. Basically, the cardiac surgeon is the end of the food chain. If indeed another specialty intervenes before cardiac surgery, the cardiac surgeon is out of luck. Truthfully, this is the fault of the cardiac surgeon. We became a highly technical specialty that has focused mostly on one operation. Therefore, we gave up the medical side of our specialty.

The only area in which I disagree with Dr Roberts is his belief that general thoracic surgery should basically split off a separate specialty. Cardiac and thoracic surgery have been linked since their inception. General thoracic surgery can be and is a separate specialty in many institutions. However, the training for cardiac and thoracic surgeons is linked. We are too small to split up into multiple subgroups. I think it would be a grave error to divide thoracic surgery from cardiac surgery. I think that flexibility is the 
answer. One should be able to train in cardiovascular surgery, cardiothoracic surgery, and congenital cardiac surgery. Perhaps one could even specialize in thoracic and vascular surgery. In fact, this is a common combination of practices in smaller towns in rural America. I believe that the leadership in thoracic surgery should embrace all of these training paradigms and encourage flexibility in the specialty. I think a surgeon becomes better by having familiarity in multiple areas. My great hope is that all of these possibilities will be available for trainees in the near future. 